\title{
Optimization of Material Coefficients in the Holzapfel-Gasser-Ogden Material Model for the Main Four Ligaments of the Knee Joint-A Finite Element Study
}

\author{
Sara Sadeqi1,2, Rodney Summers ${ }^{1}$, Deniz U. Erbulut ${ }^{1,3}$, Vijay K. Goel ${ }^{1 *}$ \\ ${ }^{1}$ Engineering Center for Orthopaedics Research Excellence (E-CORE), Departments of Bioengineering and Orthopaedics, \\ The University of Toledo, Toledo, USA \\ ${ }^{2}$ Department of Mechanical, Industrial and Manufacturing Engineering (MIME), The University of Toledo, Toledo, USA \\ ${ }^{3}$ Herston Biofabrication Institute, Metro North Hospital and Health Service, Brisbane, Australia \\ Email: Sara.sadeqi@utoledo.edu, Rodney.summers@rockets.utoledo.edu, erbulut.deniz@gmail.com deniz.erbulut@health.qld.gov.au, \\ *Vijay.goel@utoledo.edu
}

How to cite this paper: Sadeqi, S., Summers, R., Erbulut, D.U. and Goel, V.K. (2021) Optimization of Material Coefficients in the Holzapfel-Gasser-Ogden Material Model for the Main Four Ligaments of the Knee Joint-A Finite Element Study. Applied Mathematics, 12, 1166-1188.

https://doi.org/10.4236/am.2021.1212075

Received: November 1, 2021

Accepted: December 11, 2021

Published: December 14, 2021

Copyright $\odot 2021$ by author(s) and Scientific Research Publishing Inc. This work is licensed under the Creative Commons Attribution International License (CC BY 4.0).

http://creativecommons.org/licenses/by/4.0/

\begin{abstract}
Accurate representation of soft tissue material properties plays a crucial role in computational biomechanics. Several material models have been used for knee ligaments in finite element (FE) studies, including the neo-Hookean model (widely used) and the Holzapfel-Gasser-Ogden (HGO) model (seldom used). While the coefficients of neo-Hookean models for the knee ligaments are available in the literature, limited data exists for the HGO model. Furthermore, no peer-reviewed comparison of these two material models for the knee ligaments while including the 3D representation of the ligaments for both material models is present in the literature. We used mechanical properties from the tensile test experiments in the literature for each ligament to obtain the HGO material coefficients while accounting for the ligaments' viscoelastic behavior. Resultant coefficients were then used in an Abaqus/explicit knee model to simulate bipedal landing from a jump. The simulations were repeated with neo-Hookean values from the literature. Knee kinematics plus ACL and MCL strains were evaluated and compared for these two material models. The outputs from the simulations with HGO properties were predominantly within 1.5 standard deviations from the mean in-vitro data. When the material properties changed to Neo-Hookean, the outputs for kinematics and strain values were higher than the $\mathrm{HGO}$ case, and in most instances, they were outside the experimental range for ACL and MCL strains (by up to $11.35 \mathrm{SD}$ ) as well as some ITR angles (by up to $2.86 \mathrm{SD}$ ). Reported HGO material model with optimized coefficients produces a more realistic representa-
\end{abstract}


tion of the ligaments' material properties, and will help improve the outcomes of FE models for more accurate predictions of knee behavior.

\section{Keywords}

Soft Tissue, Material Properties, Holzapfel-Gasser-Ogden Constitutive Model, Dynamic Finite Element Analysis, Knee Ligaments

\section{Introduction}

Computational biomechanics, specifically FE analysis, has become an indispensable tool that assisted in-vivo and in-vitro experiments over the past few decades. Moreover, factors such as increased cost-effectiveness, the non-invasive nature of the studies, and ethical purposes of reducing the risk to human subjects have complemented its ability to decode the behavior of complex biological tissues [1] [2]. Nevertheless, a reliable FE model should accurately represent the joint geometry and material properties [3]. Determining the material properties, especially those for the soft tissues, has been a challenge in the biomechanical FE studies [4]. Knee joint computational modeling is not an exception; kinematics and the overall biomechanics of a knee joint are directly correlated to the properties assigned to the respective cruciate and collateral ligaments. Hence, it is essential to use an appropriate material model to capture the constitutive behavior of the ligaments.

A wide range of material properties has been used for ligament modeling in the literature [5]. Earlier ligament models employed one-dimensional elements with nonlinear elastic force-elongation equations for the ligaments' behavior [6]-[11]. Other studies have used the neo-Hookean [12] [13] [14] [15] [16] or Mooney-Rivlin [17] [18] material models, which are mainly isotropic and might not accurately represent the direction dependency of the ligaments. Lately, anisotropic properties based on the strain energy density function were used in several studies to suitably represent the ligaments' anisotropic behavior [19]-[25]. The equation consists of an incompressible neo-Hookean component to represent the ground substance of the connective tissues [26] and a component to model the fibrous behavior, such as in Holzapfel-Gasser-Ogden (HGO) [27] and other custom-developed constitutive models [21] [22] [23] [24]. However, none of the studies [19] [20] that used HGO-based constitutive models for the knee ligaments have accounted for the ligaments' viscoelastic behavior [28] [29] [30]. This work aimed to overcome these limitations by obtaining the HGO coefficients through optimization while considering the ligaments' viscoelastic properties and comparing knee behavior using the optimized properties and NeoHookean materials. This work differs from Kiapour et al. [19] and Beidikhti et al. [25] in that they both investigated the effect of ligament modeling techniques, i.e., using different ligament geometry representations and materials, on knee FE simulations, which makes it challenging to decide what portion of the changes in outcomes attributes to the geometry selection and what portion is related to the 
applied material model. The former [19] compared isotropic non-linear elastic properties while modeling the ligaments as a group of $2 \mathrm{D}$ truss elements and HGO material models applied to 3D knee ligaments. The latter [25] compared HGO in knee FE with 3D ligaments and simplified spring elements with non-linear stiffness. This study uses the same 3D geometries of the ligaments to better delineate the effect of different material models for both Neo-Hookean and HGO models. Viscoelastic effects were also included in both cases.

Mechanical tests have been used in the literature to obtain stress-strain curves for different hard and soft tissues, e.g., bones, ligaments, menisci, and cartilages [31]. Utilizing the accurate properties from mechanical tests for modeling ligament behavior in FE software platforms such as Abaqus requires three essential steps: 1) finding the appropriate test data, 2) choosing the proper material model to represent the anisotropic hyper-elastic behavior of the ligaments, and 3) obtaining the coefficients to use in the selected material model using curve fitting techniques. This study chose the HGO model for the main four tibiofemoral ligaments. HGO model coefficients for both pairs of cruciate and collateral ligaments were obtained using optimization schemes which utilized load-displacement data from three separate mechanical test studies for ACL [32], PCL [24], and MCL [33]. Limited representative test data were available for the LCL; thus, the data from the MCL mechanical tests were adopted to determine LCL coefficients.

The purpose of this study was to identify the coefficients in HGO model for the knee joint cruciate and collateral ligaments based on the mechanical test results. Viscoelastic behavior was also taken into account for a closer representation of the physiological biomechanics of the knee joint. The obtained material properties were then used in a dynamic FE model of the knee joint [34] under loading conditions from an in-vitro experiment [35]. Resultant joint kinematics and ligament strains were compared with FE model which uses neo-Hookean properties for the ligaments. We hypothesized that the FE model with optimized ligament properties would better match the experimental joint kinematics and ligament strains when used in a dynamic finite element model entailing other properties and characteristics from the literature. Having access to these optimized coefficients will help other researchers to be able to speed up their analyses by directly applying these values to the ligaments in their knee finite element simulations whenever they are using the HGO material model in combination with the ligaments' visco-elastic properties, without having to perform the cumbersome optimization steps for all these four knee ligaments.

\section{Materials and Methods}

\subsection{Material Property Optimization}

MR images of the knee cruciate and collateral ligaments from a healthy female subject $(23 \mathrm{yr}, 1.71 \mathrm{~m}, 60.3 \mathrm{~kg}$ ) were segmented in Mimics v15.0 (Materialise, Leuven, Belgium), smoothened in Geomagics Studio (3D Systems, Rock Hill, South Carolina), and meshed in Hypermesh v12.0 (Altair, Troy, MI, USA) using 
four-node tetrahedral elements. The 3D meshes were then imported to Abaqus/ explicit 6.14-5 (SIMULIA, Providence, RI, USA) for mesh convergence. Mesh was refined in localized regions until the stress and strain differences between two subsequent meshes were less than $5 \%$. Mechanical test data from literature were used to optimize the hyper-elastic coefficients for the HGO material model [36]. For ACL, Woo et al. [32] experimental data was used, Wan et al. [24] data was used for PCL. In order to obtain MCL coefficients, Quapp and Weiss's [33] experimental results were used, and for LCL same experimental data as MCL was used to derive the coefficients.

Ligaments were modeled as bone-ligament-bone structures in the FE simulations to replicate mechanical test conditions (Figure 1). Two block geometries were created in Abaqus to simulate the bone attachment sites for each end of the ligament. The distal bone block was fixed and the proximal block was placed under a controlled displacement via a reference point coupled to the nodes of the bone block. If literature test curves reported load-displacement data, they were converted to stress-strain curves based on the length and area of each ligament in the experiments to be applicable for optimizing the properties of ligaments with different lengths and geometries. Then they were converted back to load-displacement format based on the geometries of the ligaments used in the FE for optimizations. The displacement was applied in the same direction and orientation as per each experiment. Step time for applying the displacement in each case was calculated to reproduce the same loading rates as in the experiments. Reaction force outputs acting on the reference point were extracted to generate load-displacement curves for each ligament.

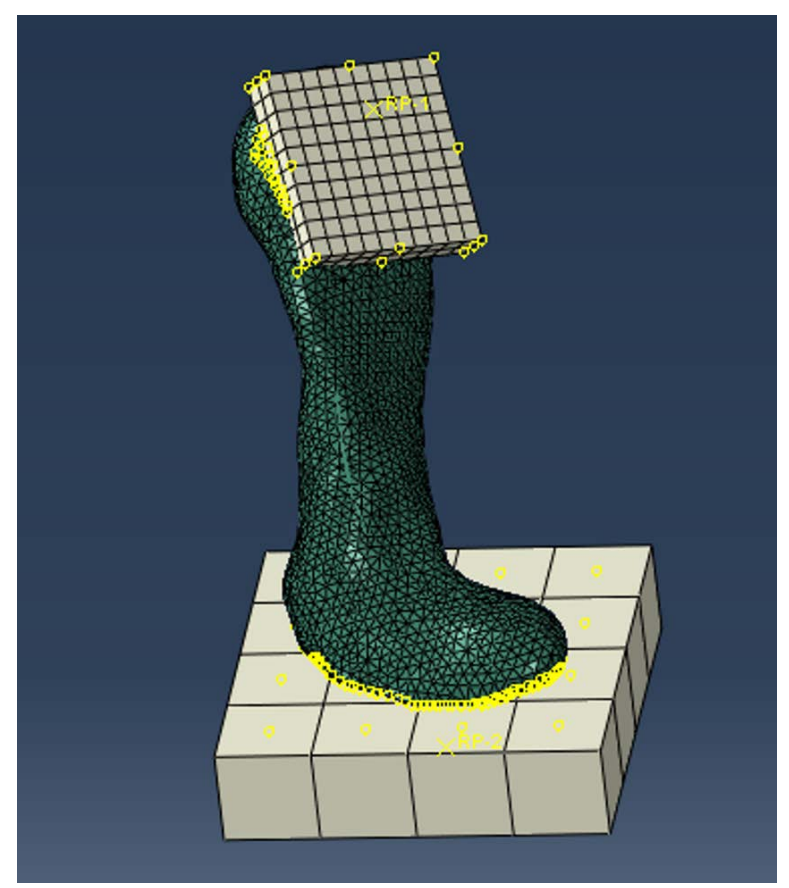

Figure 1. Bone-ligament-bone setup for ACL to simulate tension test experiments in Abaqus. 
ACL and PCL were modeled with two fiber families, while one fiber family was considered for MCL and LCL. Simulia products (Abaqus and Isight) were used to perform the optimizations. Hooke-Jeeves optimization algorithm [37] was selected to fit the load-displacement curve to that of the literature by minimizing the root mean square error and achieving a correlation greater than 0.95 . Hooke-Jeeves optimization algorithm was previously used to estimate material model coefficients of biological tissues, such as liver tissue [38] and residual limb bulk soft tissue [39]. The strain energy potential equation used in Abaqus for the anisotropic hyper-elastic HGO material model is based on Holzapfel et al. 2000 [27], and Gasser et al. 2006 [36] as follows.

$$
\begin{gathered}
U=C_{10}\left(\bar{I}_{1}-3\right)+\frac{1}{D}\left(\frac{\left(J^{e l}\right)^{2}-1}{2}-\ln J^{e l}\right)+\frac{k_{1}}{2 k_{2}} \sum_{\propto=1}^{N}\left\{\exp \left[k_{2} \bar{E}_{\propto}^{2}\right]-1\right\} \\
\text { with } \bar{E}_{\propto} \stackrel{\text { def }}{=} \kappa\left(\bar{I}_{1}-3\right)+(1-3 \kappa)\left(\bar{I}_{4(\alpha \alpha)}-1\right),
\end{gathered}
$$

where the five coefficients of $\mathrm{C} 10, \mathrm{D}, \mathrm{K} 1, \mathrm{~K} 2$, and $\kappa$ are temperature-dependent material parameters that are the user-defined inputs to the software. C10 is the Neo-Hookean constant, D is the inverse of bulk modulus and controls the incompressibility, and $\kappa$ determines the dispersion of the fibers.

Initially, the values of the $\mathrm{C} 10$ (Neo-Hookean constant) and D (the inverse of the bulk modulus) were kept fixed to the values available in the literature (Table 1 ), and optimizations were performed by varying the other three parameters. This approach worked well for both ACL and PCL. However, this did not allow for an appropriate fit for the load-displacement curves of the collateral ligaments so $\mathrm{C} 10$ and $\mathrm{D}$ were allowed to vary during the optimization process to obtain a satisfactory fit. The optimized coefficients were also tested in a simulated compression to monitor the ligaments' behaviors under compressive loads. The volumes of the ligaments used in this study are also reported in Table 2 to give the reader an idea of how close they are to their models'.

\subsection{FE Model Development}

Details on the FE models' development and validation were presented in our

Table 1. Neo-Hookean material coefficients for the knee ligaments (Pena et al., 2006).

\begin{tabular}{ccc}
\hline Ligament & C10 & $\mathrm{D}$ \\
\hline ACL & 1.95 & 0.00683 \\
PCL & 3.25 & 0.0041 \\
MCL/LCL & 1.44 & 0.00126 \\
\hline
\end{tabular}

Table 2. Ligaments volumes in $\mathrm{mm}^{3}$ for the model used in optimizations.

\begin{tabular}{ccccc}
\hline Ligament & ACL & PCL & MCL & LCL \\
\hline Volume $\left(\mathrm{mm}^{3}\right)$ & 1119 & 1873 & 2272 & 899 \\
\hline
\end{tabular}


previous work [34] and is briefly described in this section. Following IRB approval, MR images of a healthy female subject ( $23 \mathrm{yr}, 1.71 \mathrm{~m}, 60.3 \mathrm{~kg}$ ) were used for creating the 3D geometry. All bony structures and soft tissues including femur, tibia, patella, fibula, medial and lateral menisci (MM \& LM), articular cartilages (femoral; FC, medial tibial; MTC, lateral tibial; LTC, patellar; PC), and ligaments (anterior and posterior cruciate; ACL \& PCL and medial and lateral collateral; MCL \& LCL) were manually segmented in Mimics. The smoothing process of the 3D surfaces was performed in Geomagics Studio. Hypermesh was used for the subsequent mesh generation. Four-node tetrahedral elements were created and assessed for mesh quality [40] in Hypermesh, factoring into consideration the elements warpage, aspect ratio, Jacobean, and tet collapse. The final meshes had only less than $1 \%$ of elements for each part possessing warpage $>5$, aspect ratio $>3$, Jacobean $<0.7$, and tet collapse $<0.3$. Model assembly (Figure 2) and mesh convergence analysis were performed using Abaqus/explicit. The four main ligaments (ACL, PCL, MCL, and LCL) were coupled at their insertion sites to the bones. Femoral, tibial, and patellar cartilages were tied to the bones underneath them. Seven frictionless surface-to-surface interactions were defined at the contact between articular cartilages, among each other and with the menisci. Additional surface-to-surface interactions were assigned to contacts between ACL-PCL, ACL-femoral notch, and tibia-MCL. Meniscal horn attachments were modeled as kinematic couplings between the horns and the insertion site on the tibial plateau. Connector elements were used as peripheral attachments connecting the menisci to the tibia articular surface. Other capsule structures were modeled as connectors with nonlinear load-displacement data. Material properties were derived from the literature. In brief, bones were modeled as linearly elastic materials with different properties for cortical and cancellous bones [3]. Menisci were modeled as transversely isotropic materials [41]. The neo-Hookean material model was used for the articular cartilage with values
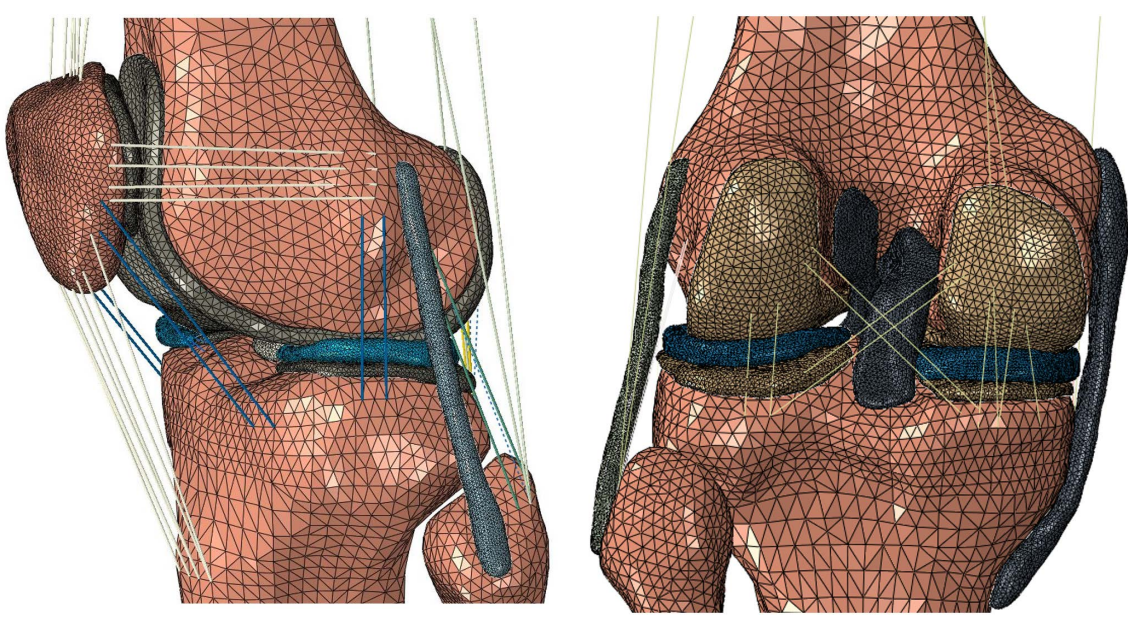

Figure 2. Knee finite element model including 3D structures for bones, cartilages, menisci, and four main ligaments, and 2D connectors for patellofemoral attachments and knee capsule. 
calculated from young's modulus and Poisson's ratio [42]. The four main ligaments were modeled as hyper-elastic materials according to HGO [36], with coefficients obtained through the curve fitting process based on experimental data, as is described above in the material properties optimization section. Lastly, viscoelastic properties were applied to cruciate and collateral ligaments by assigning stress relaxation data using time-based prony series [43].

\subsection{FE Simulations}

Load cases examined included various combinations of knee abduction moment (KAM), internal tibial rotation moment (ITR), and anterior tibial shear force (ATS) followed by an axial compression force equal to the impact load of half a bodyweight dropping from a $30 \mathrm{~cm}$ height, simulating bipedal landing from a jump (Table 3). All analyses were done with the knee flexed to 25 degrees. Muscle forces of $441 \mathrm{~N}$ were applied to quadriceps; for counterbalance, the same amount of force $(441 \mathrm{~N})$ was considered for hamstring muscles, equally distributed among the lateral and medial hamstring groups. The biceps femoris long head was used for applying the lateral hamstring load, and the semitendinosus, semimembranosus, and gracilis were used for the medial side. Analyses were done using Abaqus explicit solver [44]. Readers may refer to Erbulut et al. 2021 [34] for more details on the loads and boundary conditions.

FE simulations were performed once using the optimized properties and once using the Neo-Hookean properties; viscoelastic behavior was considered in both cases. Outputs for knee kinematics (valgus/varus angle, internal/external tibial rotation angle, anterior/posterior tibial translation, and superior/inferior tibial translation) along with ACL and MCL strains were extracted and compared.

\section{Results}

\subsection{Ligament Material Property Optimization}

Comparison between the load-displacement curves obtained from literature with those of the optimized properties showed a high correlation $(r>0.95)$ for all the four knee ligaments (Table $4 \&$ Figures 3-6). Moreover, these properties were

Table 3. Loading scenarios simulating sub-failure loadings of knee abduction moment (KAM), anterior tibial shear force (ATS), and internal tibial rotation moment (ITR), determined with regard to the in vivo population percentage (\%) (Bates et al., 2017), followed by the axial impact of a drop load equal to half a bodyweight.

\begin{tabular}{ccccc}
\hline Loading Cases & $\begin{array}{c}\text { Knee abduction moment (KAM) } \\
(\mathrm{Nm}) \text {-corresponding to the } i n \\
\text { vivo population percentage (\%) }\end{array}$ & $\begin{array}{c}\text { Anterior tibial shear force } \\
\text { (ATS) (N) -corresponding } \\
\text { to the in vivo population } \\
\text { percentage (\%) }\end{array}$ & $\begin{array}{c}\text { Internal tibial rotation moment } \\
\text { (ITR) (Nm) -corresponding } \\
\text { to the in vivo population } \\
\text { percentage (\%) }\end{array}$ & $\begin{array}{c}\text { Vertical impact } \\
\text { load }\end{array}$ \\
\hline Case \#1 & $26.76 \mathrm{Nm}-67 \%$ & $80.35 \mathrm{~N}-67 \%$ & $18.62 \mathrm{Nm}-67 \%$ & $0.5 * \mathrm{BW}$ \\
Case \#2 & $57.34 \mathrm{Nm}-100 \%$ & $80.35 \mathrm{~N}-67 \%$ & $9.73 \mathrm{Nm}-33 \%$ & $0.5 * \mathrm{BW}$ \\
Case \#3 & $57.34 \mathrm{Nm}-100 \%$ & $80.35 \mathrm{~N}-67 \%$ & $18.62 \mathrm{Nm}-67 \%$ & $0.5 * \mathrm{BW}$ \\
Case \#4 & $57.34 \mathrm{Nm}-100 \%$ & $196.13 \mathrm{~N}-100 \%$ & $18.62 \mathrm{Nm}-67 \%$ & $0.5 * \mathrm{BW}$ \\
\hline
\end{tabular}


Table 4. Holzapfel-Gasser-Ogden material model coefficients for the knee main ligaments obtained via optimization, and the correlation coefficients.

\begin{tabular}{ccccccc}
\hline Ligament & C10 & D & K1 & K2 & kappa & Correlation \\
\hline ACL & 1.95 & 0.00683 & 22.627 & 471.255 & 0.0048 & 0.977 \\
PCL & 3.25 & 0.0041 & 4.836 & 139.750 & 0.000556 & 0.956 \\
MCL & 3.48 & 0.000287 & 21.489 & 179.544 & 0 & 0.962 \\
LCL & 1.35 & 0.000745 & 33.641 & 14.378 & 0 & 0.959 \\
\hline
\end{tabular}

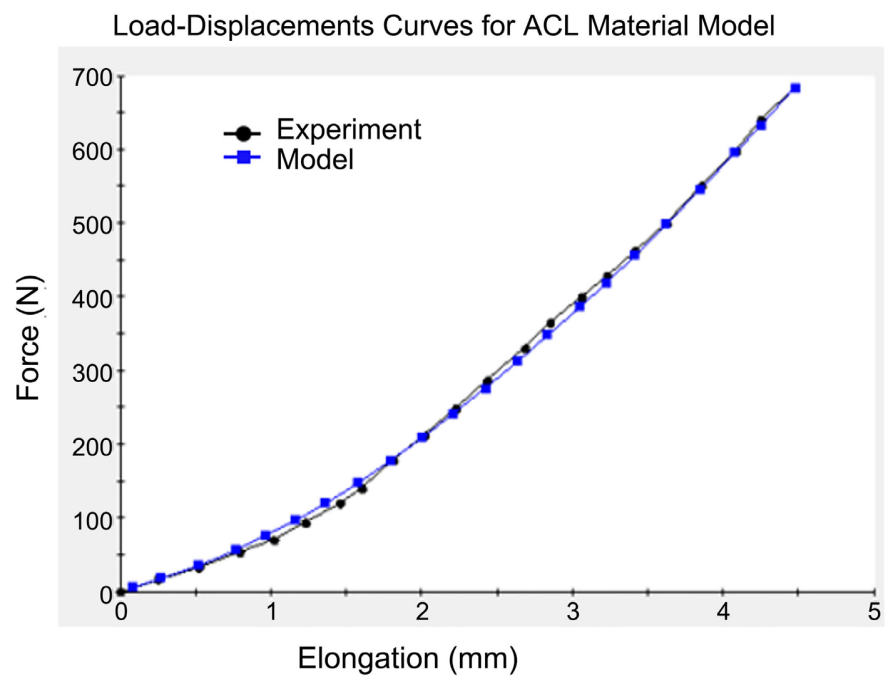

Figure 3. ACL curve fitting from Simulia iSight. The horizontal axis shows displacement in $\mathrm{mm}$, and the vertical axis displays force in $\mathrm{N}$. The black curve is the experimental data from the literature, and the blue curve is the load-displacement curve from the optimization.

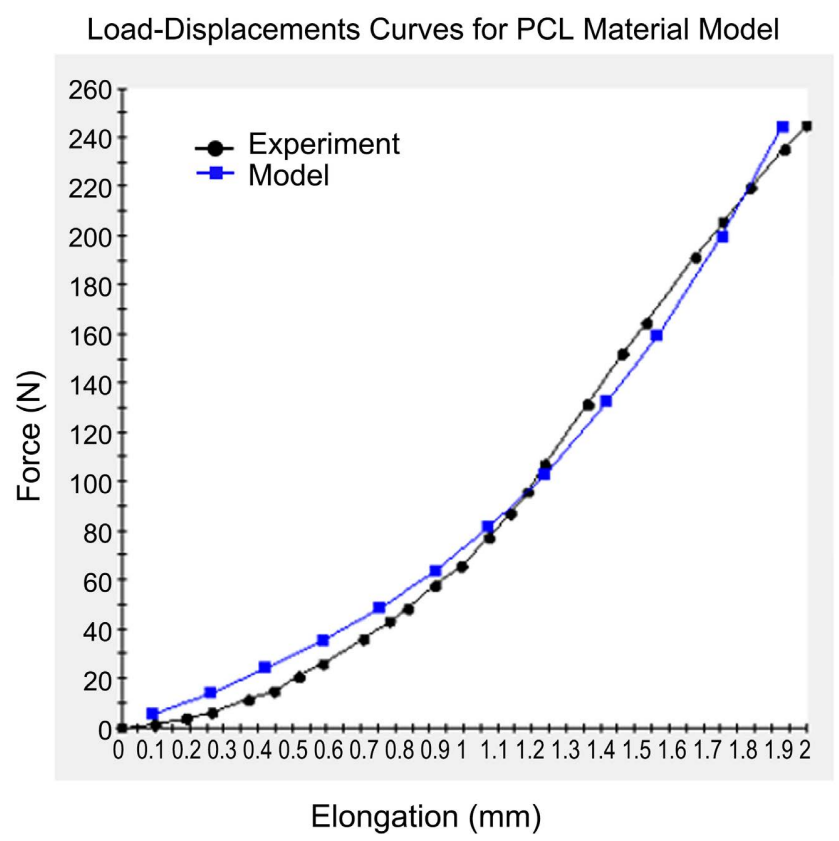

Figure 4. PCL curve fitting from Simulia iSight. The horizontal axis shows displacement in $\mathrm{mm}$, and the vertical axis displays force in $\mathrm{N}$. The black curve is the experimental data from the literature, and the blue curve is the load-displacement curve from the optimization. 


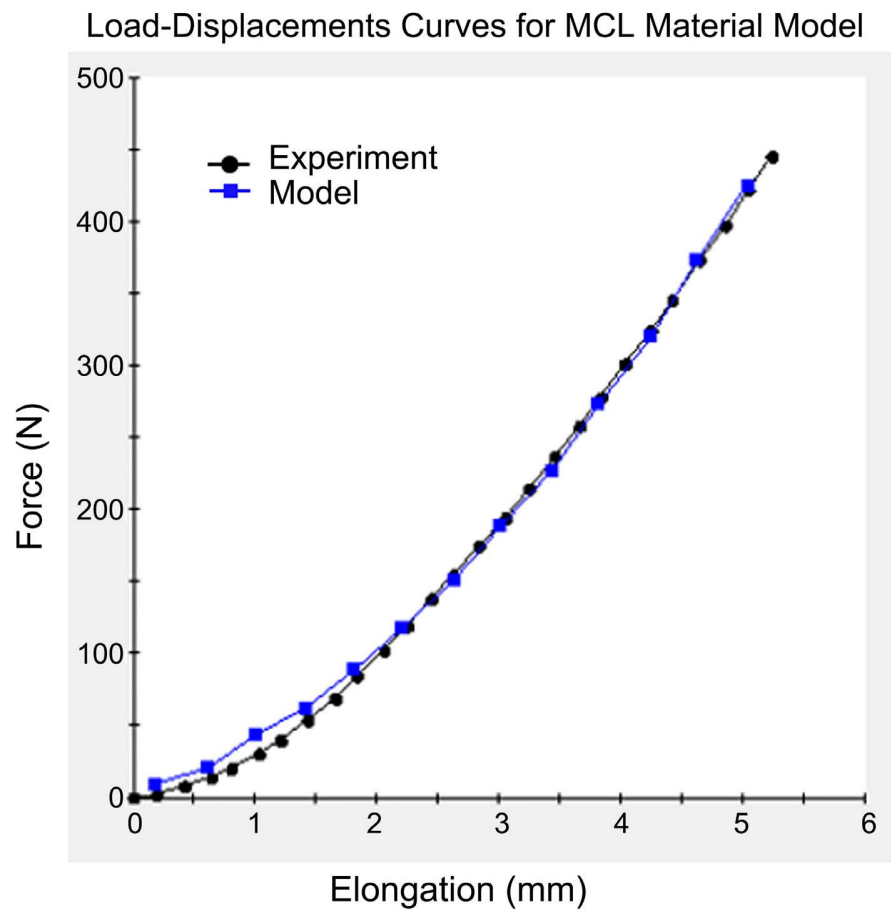

Figure 5. MCL curve fitting from Simulia iSight. The horizontal axis shows displacement in $\mathrm{mm}$, and the vertical axis displays force in $\mathrm{N}$. The black curve is the experimental data from the literature, and the blue curve is the load-displacement curve from the optimization.

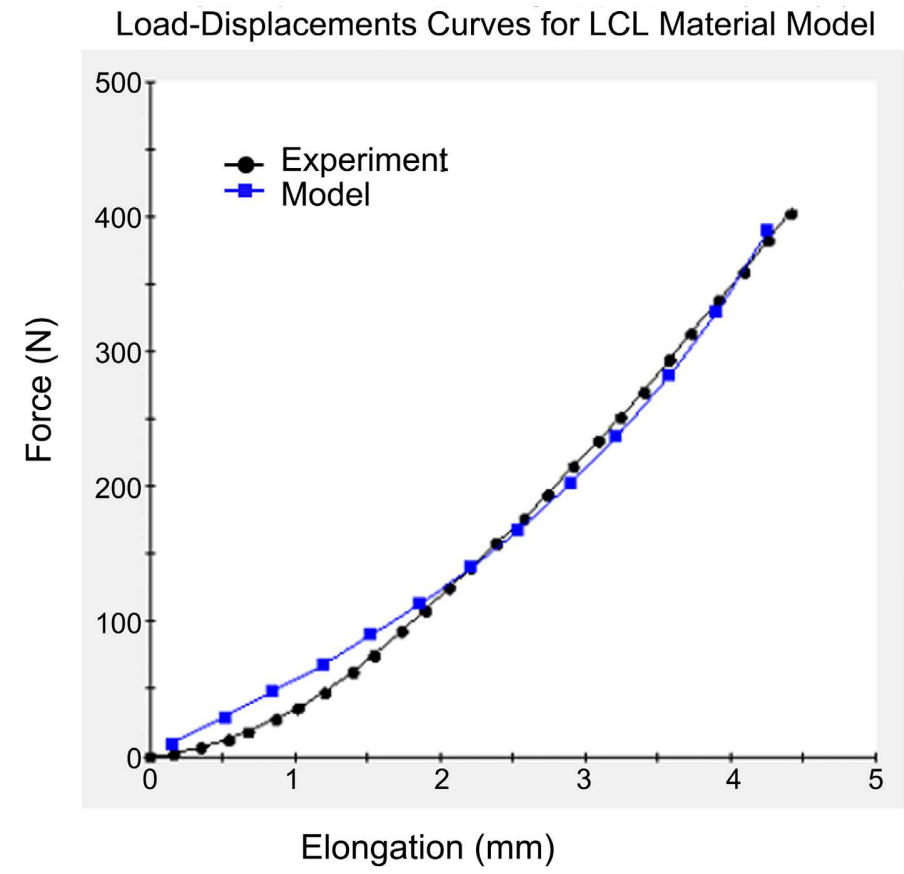

Figure 6. LCL curve fitting from Simulia iSight. The horizontal axis shows displacement in $\mathrm{mm}$, and the vertical axis displays force in $\mathrm{N}$. The black curve is the experimental data from the literature, and the blue curve is the load-displacement curve from the optimization.

used in five subject-specific FE knee models and produced the kinematics and ligament strains largely in range of 1.5 standard deviation (SD) of the mean 
in-vitro data [35], which supports the initial hypothesis. The outcomes looked at for validation included internal tibial rotation angles, knee abduction angles, anterior tibial translations, axial compressions and ACL and MCL strains. When used in a simulated compression, these properties showed no resistance under compressional loads, which ensures the incompressibility of the ligament behavior.

\subsection{FE Simulations of Bipedal Landings}

Kinematic outputs from the experimental data were reported with respect to baseline kinematics at $25^{\circ}$ knee flexion. Results from the FE simulations follow this same convention (Table $5 \&$ Table 6, and Figures 7-10). Results are presented at $33 \mathrm{~ms}, 66 \mathrm{~ms}$, and $100 \mathrm{~ms}$ after axial impact loading, the determined time course for ACL rupture following landing [45] [46].

Table 5. Knee joint kinematics for load cases $1-4$ at 33, 66, and $100 \mathrm{~ms}$ after initial ground contact. Green marks the values in the range of one standard deviation from the mean in in-vitro experiments, blue marks the values within the 1.5 standard deviation range, and orange marks the values outside this range.

\begin{tabular}{ccccccccccccccc}
\hline & \multicolumn{3}{c}{} & \multicolumn{3}{c}{ ITR (deg.) } & \multicolumn{3}{c}{ Valgus (deg.) } & \multicolumn{3}{c}{ ATT (mm) } & \multicolumn{3}{c}{ Axial Compression (mm) } \\
\hline \multirow{2}{*}{} & Time (ms) & 33 & 66 & 100 & 33 & 66 & 100 & 33 & 66 & 100 & 33 & 66 & 100 \\
\hline \multirow{2}{*}{ Case 1 } & Optimized HGO & 6.12 & 4.88 & 4.68 & 1.17 & 1.06 & 0.93 & 0.39 & 0.75 & 0.49 & 0.7 & 0.2 & 0.16 \\
& Neo-Hook & 8.64 & 5.49 & 6.42 & 1.72 & 1.82 & 1.87 & 0.58 & 1.84 & 1.29 & 0.93 & 0.14 & 0.18 \\
\hline \multirow{2}{*}{ Case 2 } & Optimized HGO & 2.65 & 0.84 & 0.64 & 1.27 & 1.35 & 1.25 & 0.09 & 0.76 & 0.37 & 0.6 & -0.002 & -0.01 \\
& Neo-Hook & 7.52 & 1.88 & 0.68 & 1.78 & 2.59 & 4.93 & 0.56 & 2.82 & 3.43 & 0.9 & -0.28 & -1.3 \\
\hline \multirow{2}{*}{ Case 3 } & Optimized HGO & 5.38 & 3.91 & 3.68 & 1.57 & 1.57 & 1.45 & 0.42 & 0.9 & 0.59 & 0.69 & 0.14 & 0.11 \\
& Neo-Hook & 10.84 & 5.52 & 4.86 & 2.94 & 3.51 & 5.19 & 1.39 & 3.43 & 3.66 & 1.13 & 0.02 & -0.78 \\
\hline \multirow{2}{*}{ Case 4 } & Optimized HGO & 5.53 & 4.14 & 3.75 & 1.62 & 1.63 & 1.49 & 0.62 & 1.08 & 0.76 & 0.69 & 0.16 & 0.12 \\
& Neo-Hook & 10.91 & 5.35 & 4.3 & 2.98 & 3.64 & 5.59 & 1.82 & 3.91 & 4.27 & 1.15 & -0.003 & -0.95 \\
\hline
\end{tabular}

Table 6. Knee joint ligament strains for load cases 1 - 4 at 33, 66, and $100 \mathrm{~ms}$ after initial ground contact. Green marks the values in the range of one standard deviation from the mean in in-vitro experiments, blue marks the values within the 1.5 standard deviation range, and orange marks the values outside this range.

\begin{tabular}{cccccccc}
\hline & & \multicolumn{3}{c}{ ACL Strain (\%) } & \multicolumn{3}{c}{ MCL Strain (\%) } \\
\hline \multirow{2}{*}{ Case 1 } & Optimized HGO & 0.01 & 2.4 & 1.75 & -0.2 & -0.07 & -0.07 \\
& Neo-Hook & 7.22 & 11.96 & 10.34 & 13.26 & 12.3 & 12.59 \\
\hline \multirow{2}{*}{ Case 2 } & Optimized HGO & -1.34 & 2.18 & 1.07 & -0.15 & -0.05 & -0.04 \\
& Neo-Hook & 7.16 & 15.52 & 19.55 & 14.62 & 12.28 & 17.48 \\
\hline \multirow{2}{*}{ Case 3 } & Optimized HGO & -0.06 & 2.77 & 1.95 & -0.18 & -0.05 & -0.06 \\
& Neo-Hook & 9.86 & 17.58 & 19.84 & 16.87 & 14.15 & 17.93 \\
\hline \multirow{2}{*}{ Case 4 } & Optimized HGO & 0.57 & 3.33 & 2.48 & -0.18 & -0.04 & -0.05 \\
& Neo-Hook & 11.22 & 19.27 & 22.17 & 16.81 & 13.98 & 18.43 \\
\hline
\end{tabular}




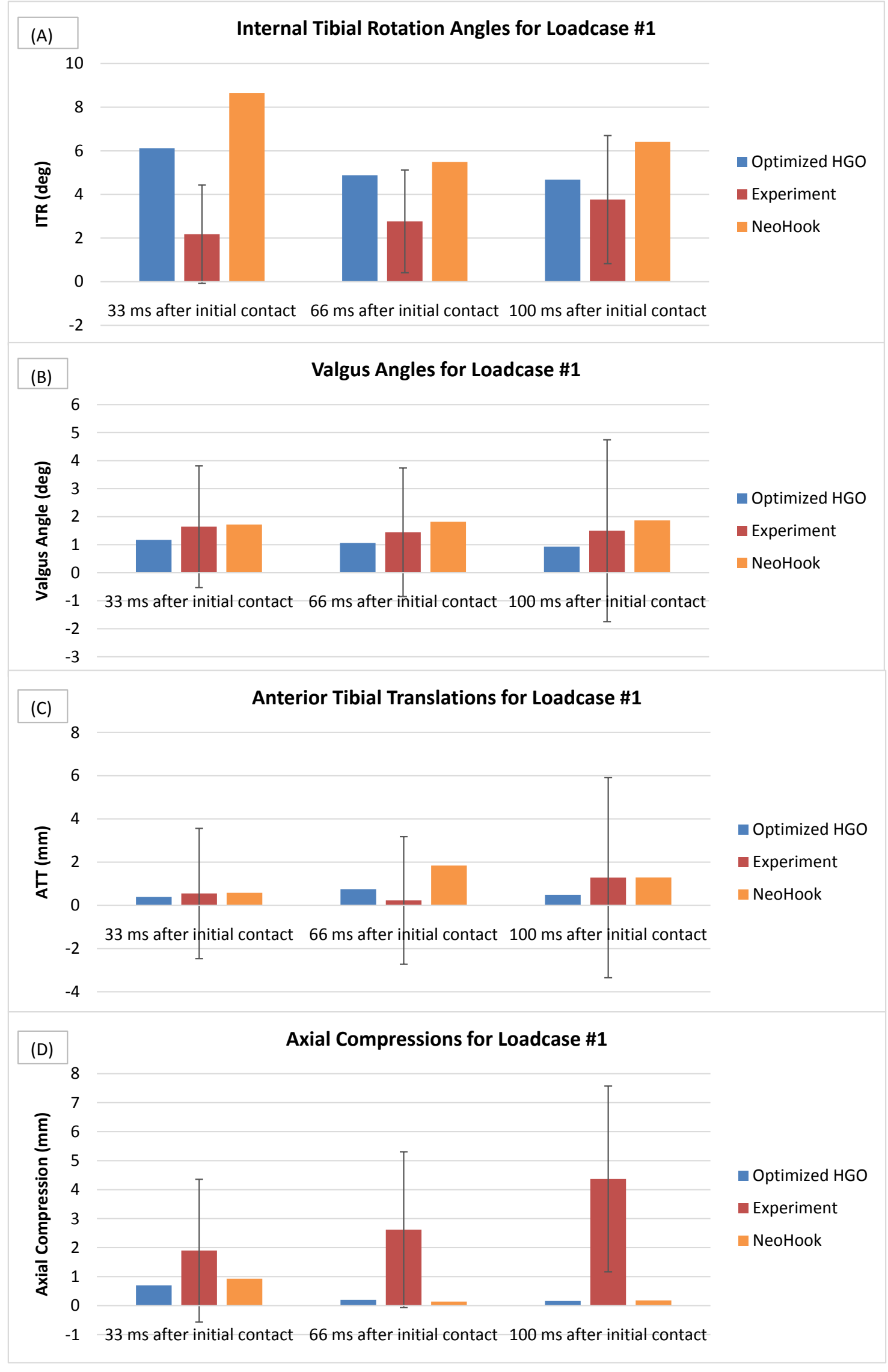




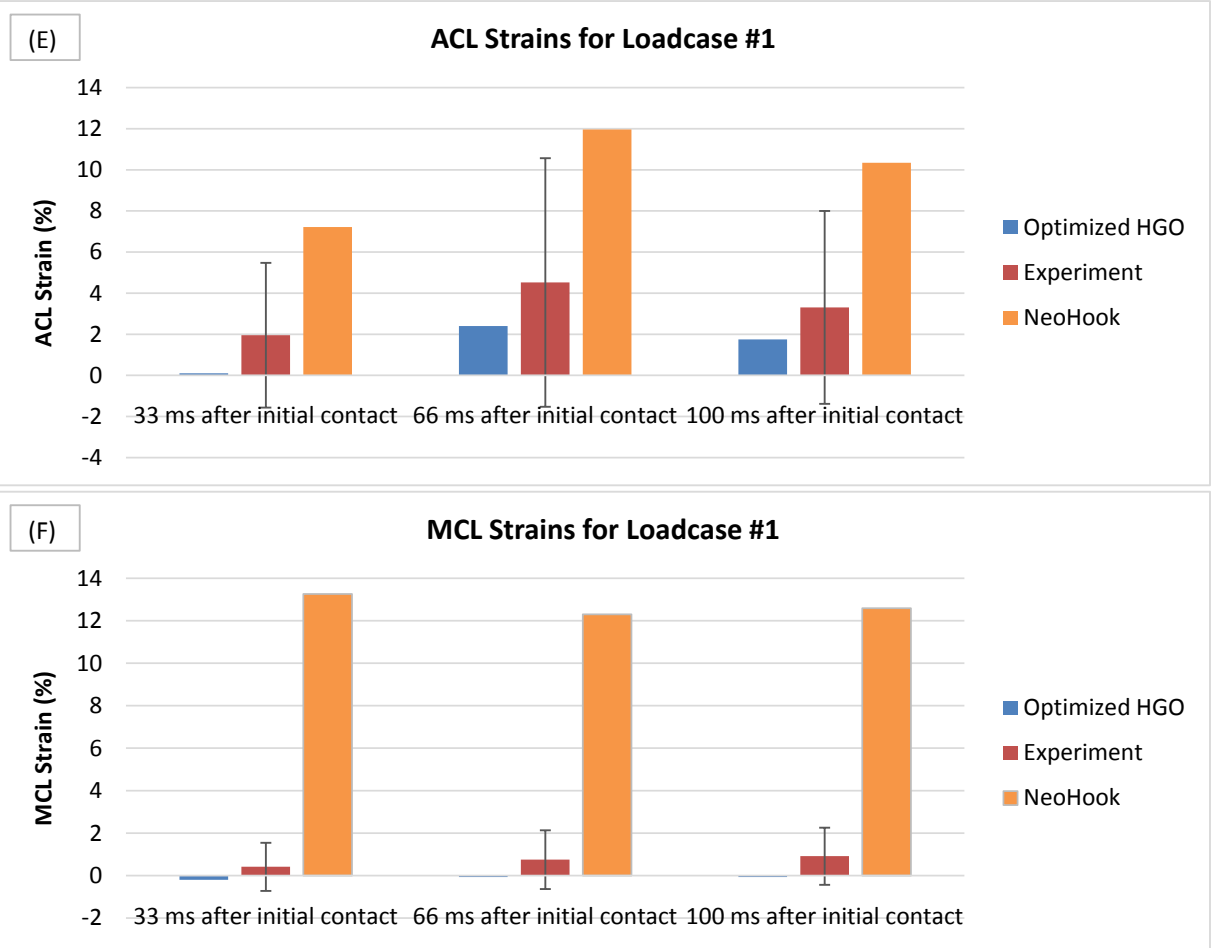

Figure 7. Knee joint kinematics and ligaments strain values from FE simulations with optimized HGO materials for ligaments (blue), FE simulations with Neo-Hookean materials for ligaments (orange), and in-vitro experiments (red) with standard deviations error bars for load case \#1 at 33, 66, and $100 \mathrm{~ms}$ after initial contact. (A) Internal tibial rotation angles, (B) Valgus angles, (C) Anterior tibial translations, (D) Axial compressions, (E) ACL strains, and (F) MCL strains.

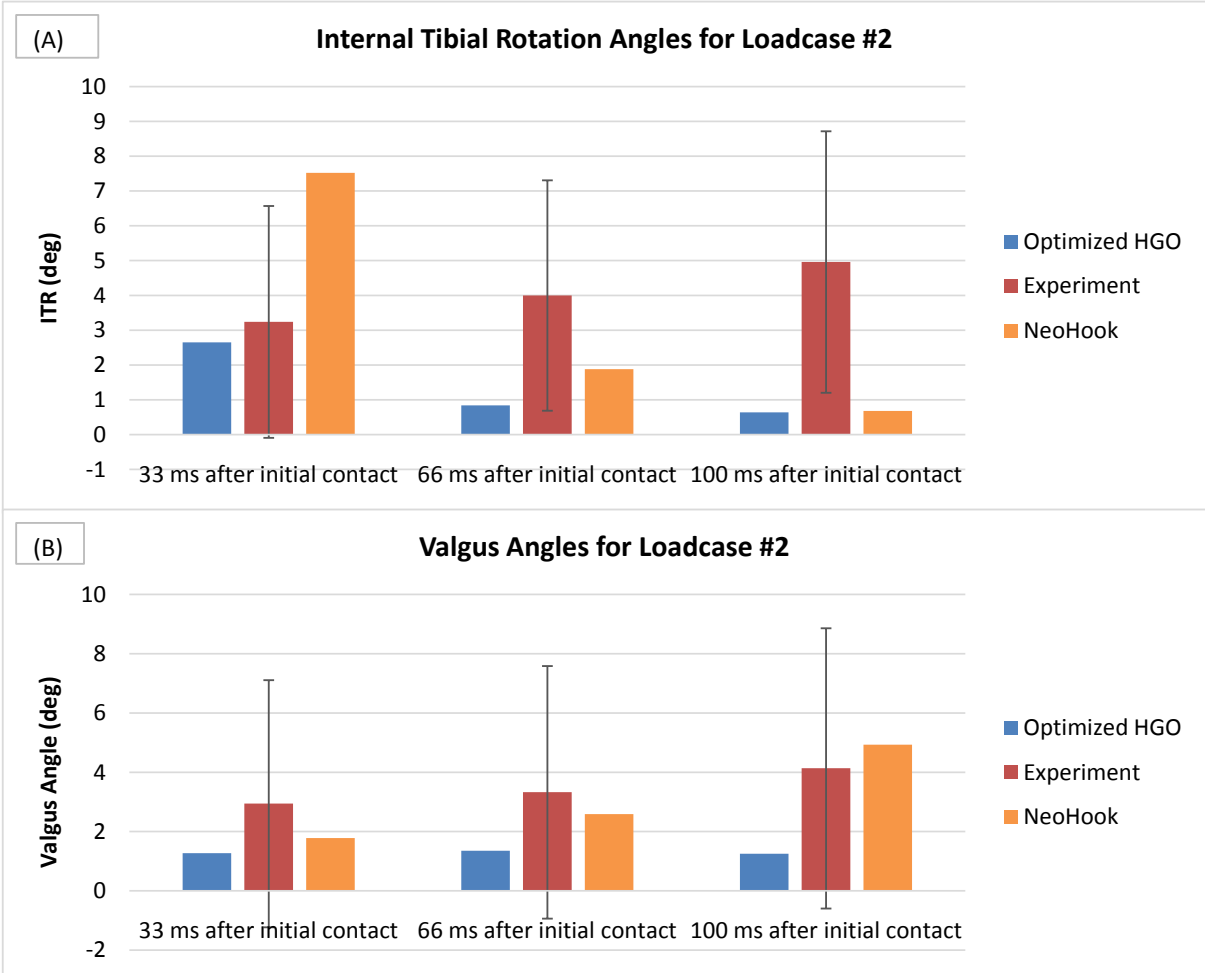




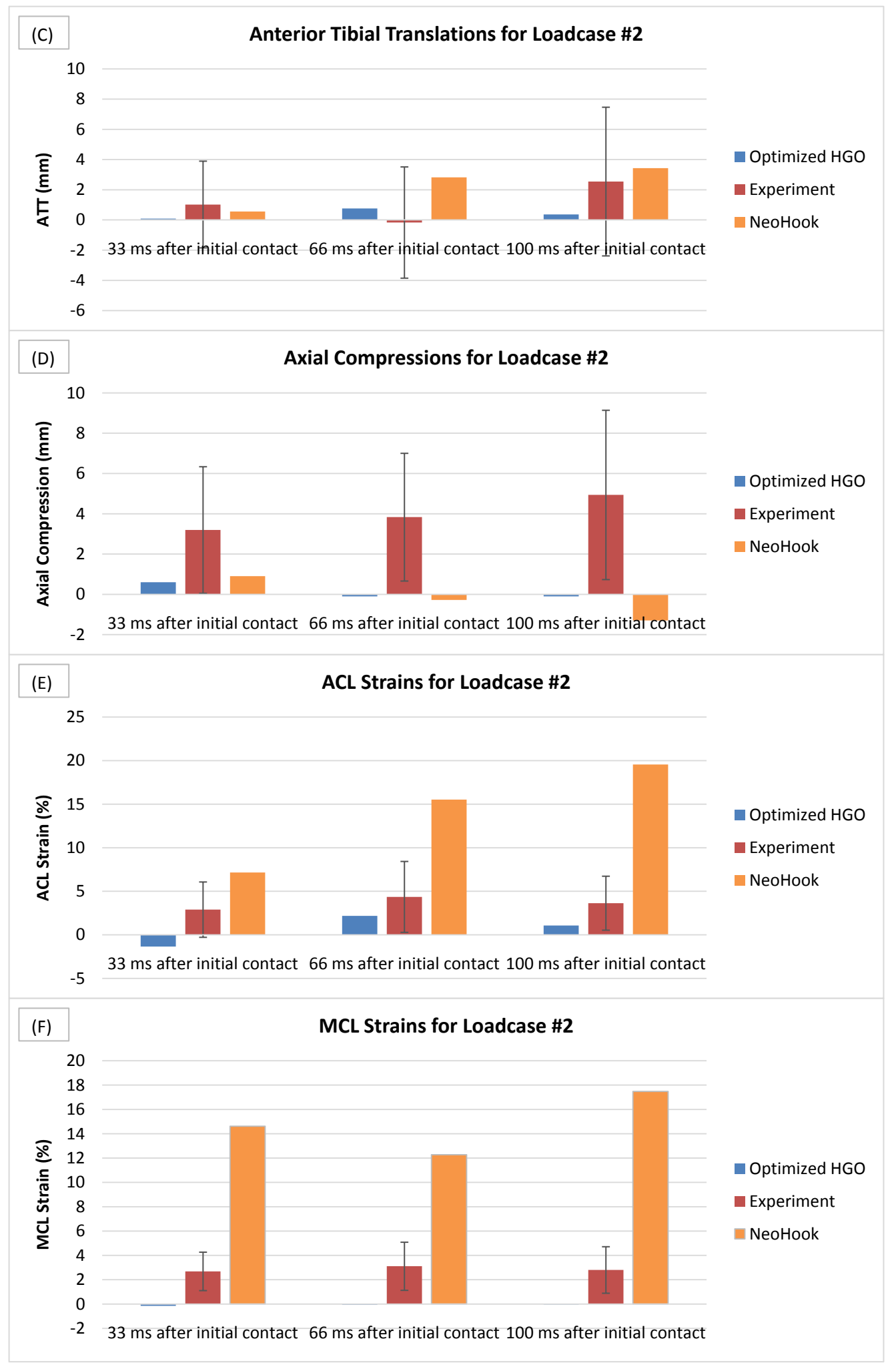

Figure 8. Knee joint kinematics and ligaments strain values from FE simulations with optimized HGO materials for ligaments (blue), FE simulations with Neo-Hookean materials for ligaments (orange), and in-vitro experiments (red) with standard deviations error bars for load case \#2 at 33, 66, and $100 \mathrm{~ms}$ after initial contact. (A) Internal tibial rotation angles, (B) Valgus angles, (C) Anterior tibial translations, (D) Axial compressions, (E) ACL strains, and (F) MCL strains. 


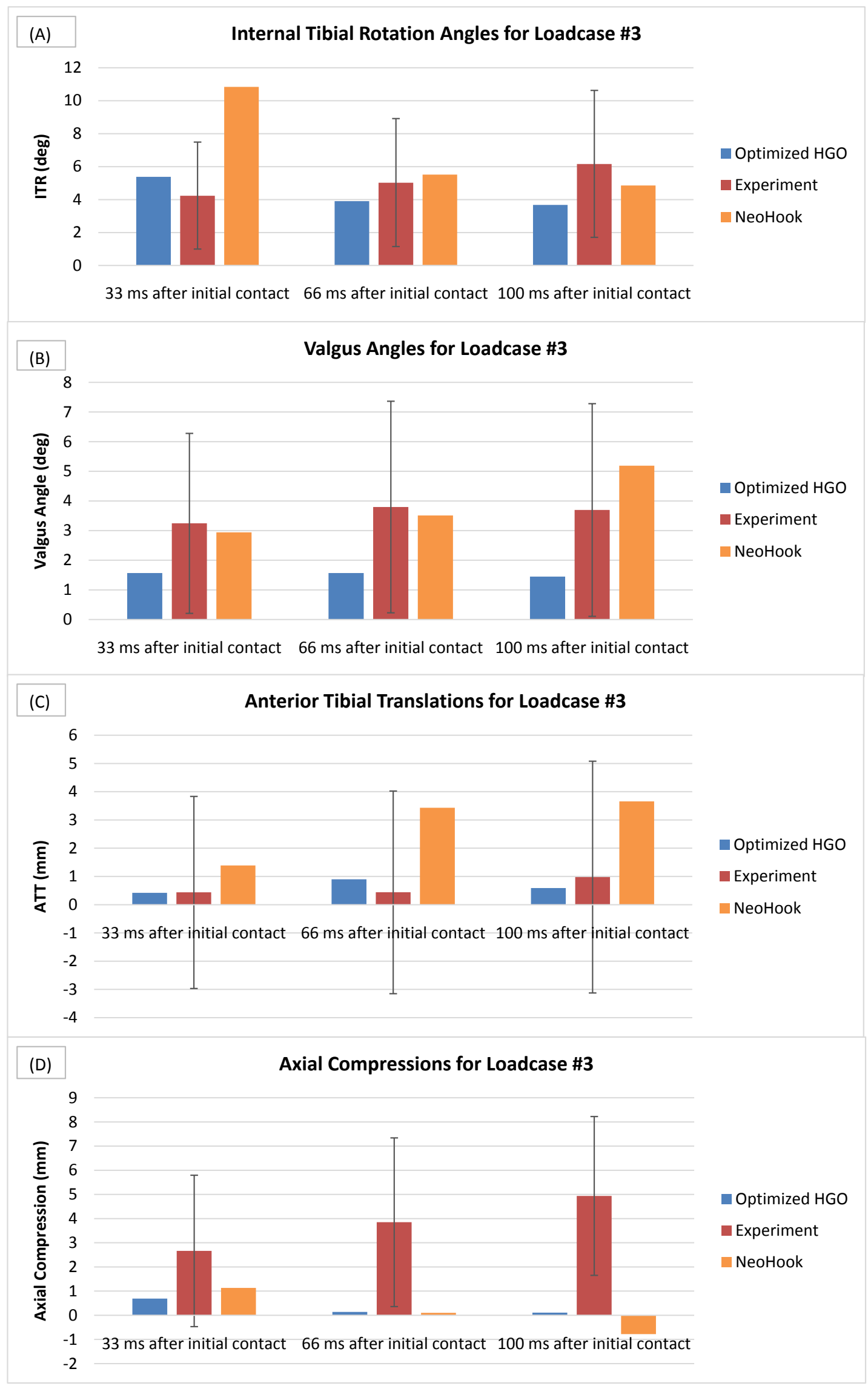




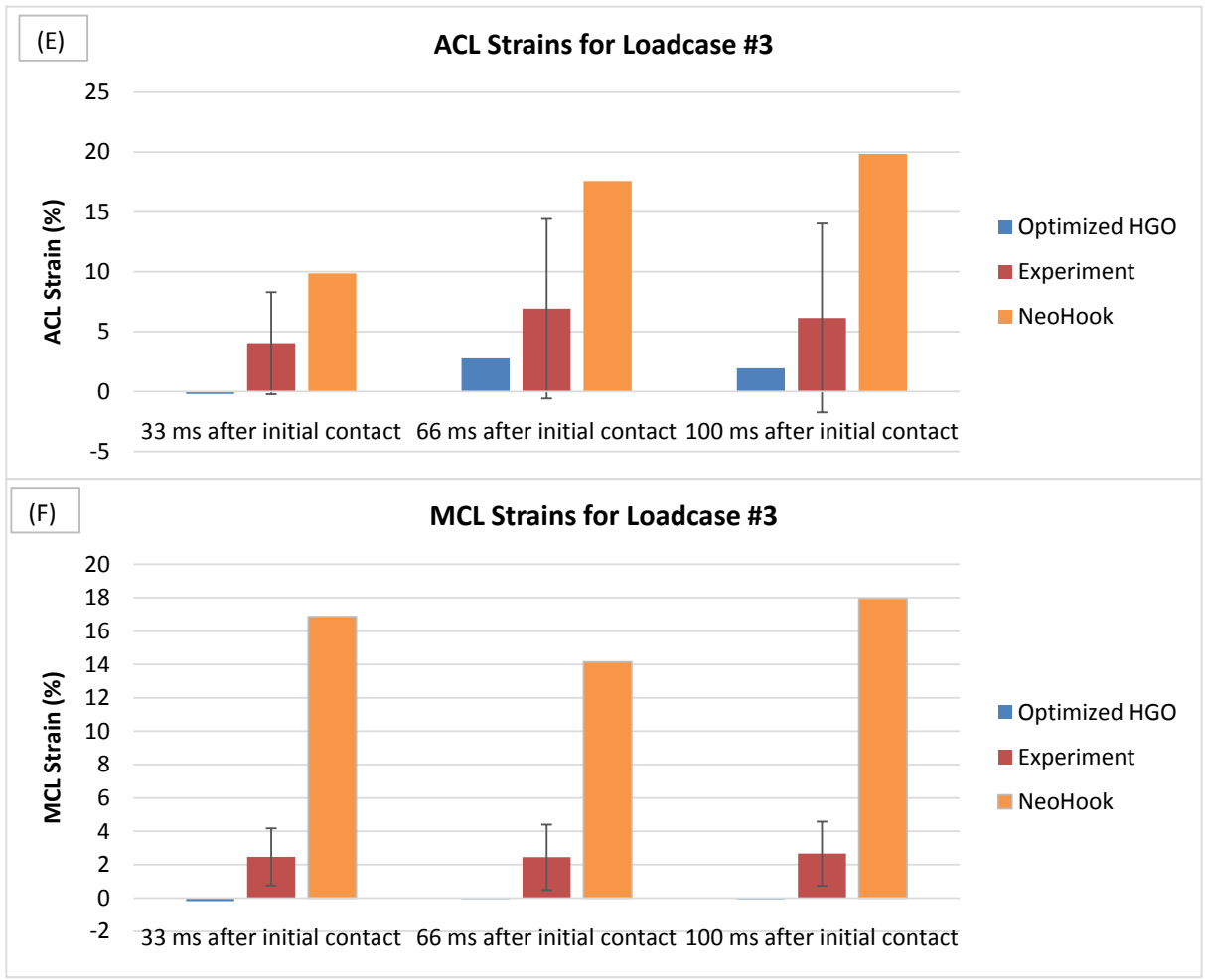

Figure 9. Knee joint kinematics and ligaments strain values from FE simulations with optimized HGO materials for ligaments (blue), FE simulations with Neo-Hookean materials for ligaments (orange), and in-vitro experiments (red) with standard deviations error bars for load case \#3 at 33, 66, and $100 \mathrm{~ms}$ after initial contact. (A) Internal tibial rotation angles, (B) Valgus angles, (C) Anterior tibial translations, (D) Axial compressions, (E) ACL strains, and (F) MCL strains.

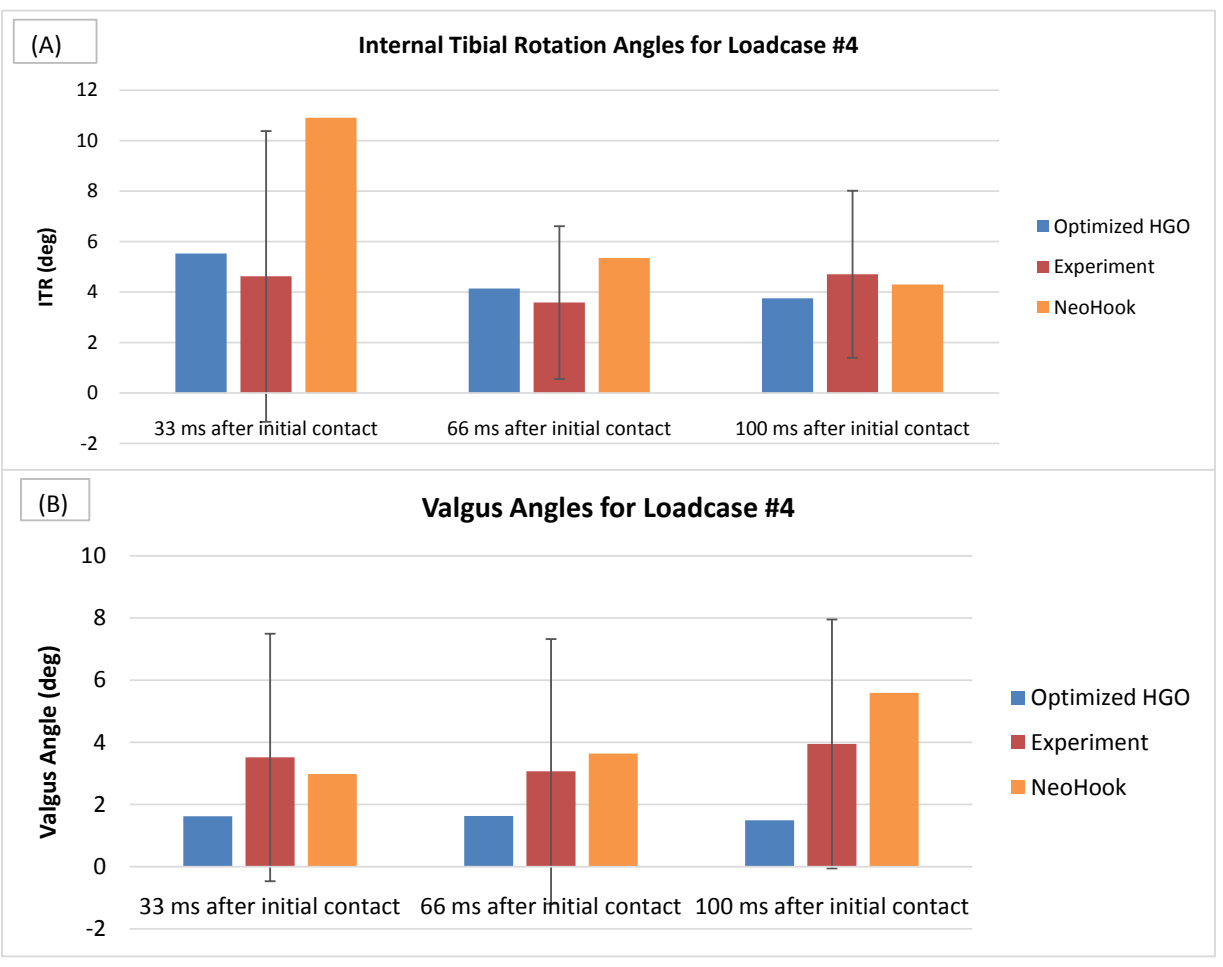




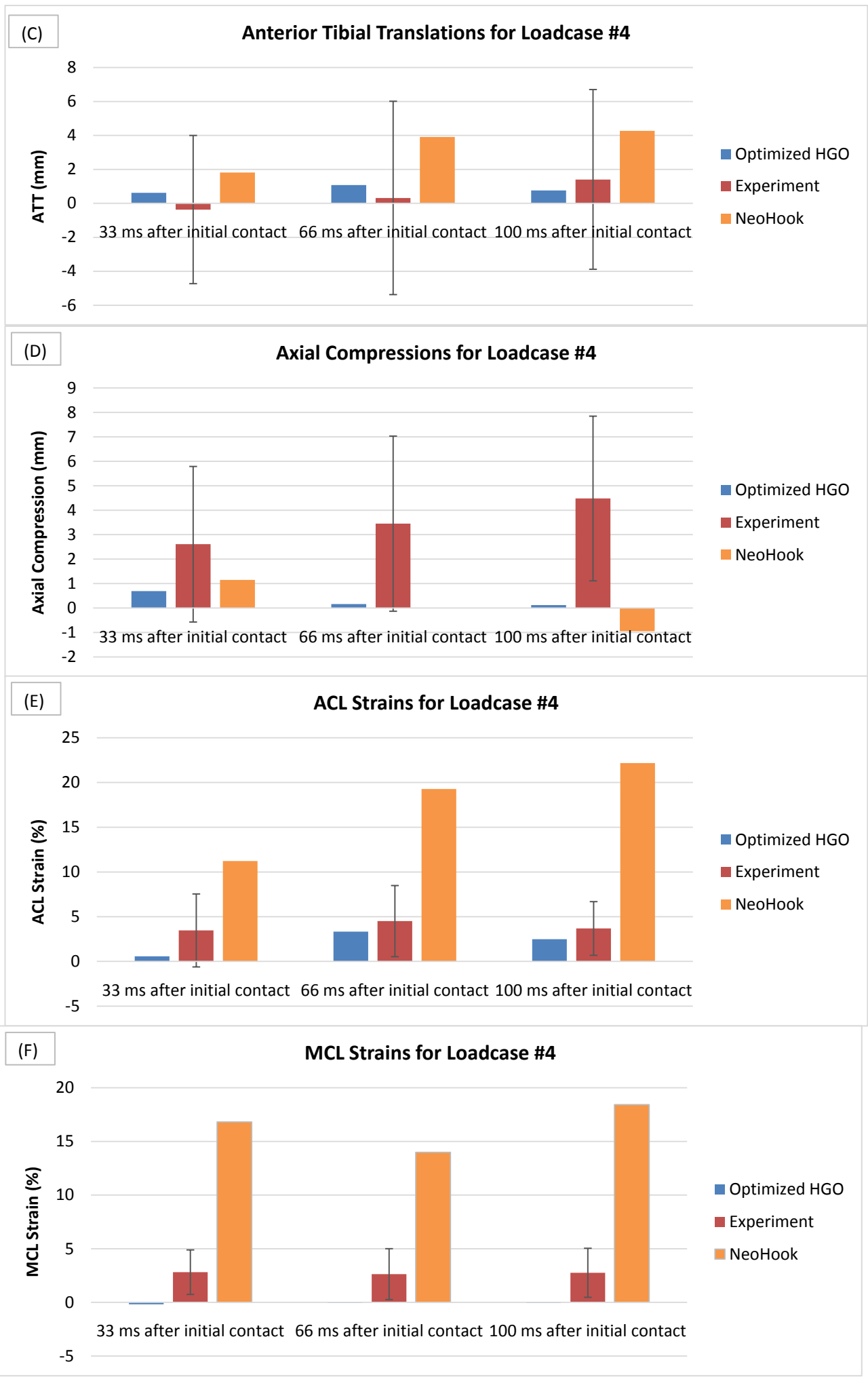

Figure 10. Knee joint kinematics and ligaments strain values from FE simulations with optimized HGO materials for ligaments (blue), FE simulations with Neo-Hookean materials for ligaments (orange), and in-vitro experiments (red) with standard deviations error bars for load case \#4 at 33, 66, and $100 \mathrm{~ms}$ after initial contact. (A) Internal tibial rotation angles, (B) Valgus angles, (C) Anterior tibial translations, (D) Axial compressions, (E) ACL strains, and (F) MCL strains. 
Valgus angles and anterior tibial translations were within 1SD of experimental mean data for both materials in all four examined load cases. In total, the simulations with HGO materials led to a closer match with the outputs from in-vitro experiments, with only four data points outside $1.5 \mathrm{SD}$, compared to the simulations with Neo-Hookean materials (22 data points outside 1.5SD).

For ITR angles, most data were in the range of experimental outputs for the simulations with HGO materials, except for load case 1 at $33 \mathrm{~ms}$ and load case 2 at $100 \mathrm{~ms}$, which lay outside the $1.5 \mathrm{SD}$ and $1 \mathrm{SD}$ from the experimental mean, respectively. For the models with Neo-Hookean materials, most ITR angles were in the range of experiments as well; except at $33 \mathrm{~ms}$ for load cases $1 \& 3$, which were outside the $1.5 \mathrm{SD}$ range while load cases $2 \& 4$ at $33 \mathrm{~ms}$, load cases $1 \& 2$ at $100 \mathrm{~ms}$, and load case 1 at $66 \mathrm{~ms}$ time point had results outside 1SD from the mean experiments.

In the case of axial compressions, all outputs at $33 \mathrm{~ms}$ time points for both materials in all load cases were in the range of in-vitro outputs. At $66 \mathrm{~ms}$ after initial contact, load cases $2 \& 3$ had outside 1SD data for both materials. At 100 ms, all data were outside the 1SD range for both HGO and Neo-Hook; however, models with Neo-Hookean materials outputs at this time point were also outside the $1.5 \mathrm{SD}$ margin for load cases $3 \& 4$.

None of the ACL and MCL outputs from the simulations with Neo-Hookean materials were in the range of $1 \mathrm{SD}$ from the mean experimental values; and for load case \#4, the highest loads, all strain values from the models with Neo-Hookean materials were outside the 1.5SD margin (orange cells in Table 6, bottom row).

\section{Discussion}

Accuracy in modeling soft tissues is of great importance in computational biomechanics [47], and small variations in their properties will result in significant changes in the FE outputs. Knee ligaments are not an exception, and their properties will directly affect the knee joint kinematics and soft and hard tissue stresses and strains. The considerable differences in joint kinematics and ligament strains after changing the hyper-elastic material model of the main knee ligaments in this study proved this point and confirmed the sensitivity of joint biomechanics to these properties in FE simulations.

In this study, the HGO hyper-elastic material parameters for the main knee ligaments were identified via optimization for use in finite element studies. The ACL showed the best match among all the optimized properties, most likely due to a more robust data set available in the literature for ACL mechanical testing. For example, limited studies evaluated mechanical properties of the LCL, specifically no mechanical test data could be found for the human LCL for the young population in the literature. Most studies that reported LCL mechanical properties [48] [49] [50] [51] performed tensile test experiments on elderly cadavers, e.g. ( $81 \pm 11$ yrs. old) in [48] (74 \pm 7 yrs. old) in [49], (77.1 \pm 9.6 yrs. old) in [50], and 71 yrs old in [51]. Therefore, we did not find those appropriate for this 
study that simulates landing from a jump in young athletes. Also, only a few studies were found for the PCL and MCL. Therefore, getting the accurate properties would be more difficult for these three ligaments relative to ACL. Nevertheless, all the four ligaments' optimized coefficients presented high correlations ( $r>$ $0.95)$.

Special care should be given to using these properties in other knee FE models if the modeling technique varies substantially, such as not applying viscoelastic effects. Also, it should be considered that coefficients obtained from optimization of material properties are not unique [52] and the purpose of this work was to present a set of data that were validated against in-vitro experiments. Although the proposed coefficients belong to one specific subject, they have been tested in five different subject-specific models in the validation process. Other modelers can apply these properties to help with their progress; they can also use the tools presented here to perform optimizations of their own.

Another important aspect while simulating soft tissue material properties is the conditions of experimental tension tests used. For instance, failure force, failure elongations, and other tensile properties of femur-ACL-tibia complex have been compared for fresh cadaveric specimens versus formalin preserved or deepfrozen preserved, and it has been demonstrated that the preservation method causes significant changes in the ligaments' mechanical properties [53]. The experiments used in this study utilized fresh frozen samples for MCL [33], $-20^{\circ} \mathrm{C}$ frozen preserved for PCL [24], and ACL [32]. This study used more current test data (2015) for PCL [24] and from younger specimens for both PCL (30 yr old) [24] and ACL (mean $=29 \mathrm{yr}$ old, $22-35 \mathrm{yr}$ ) [32] as opposed to the relatively older data [54] used by other studies for ACL and PCL (38 yr old).

The comparison between our optimized HGO coefficients vs. Neo-Hookean coefficients from the literature showed that HGO with optimized coefficients could produce outputs closer to the experimental data; this was expected because of the directionally dependent behavior of ligaments that the Neo-Hookean model does not permit [55], along with the more physiologically relevant coupling of fiber and ground matrix contributions provided in the HGO model. NeoHookean material led to larger strains in the FE simulations; this could be because there is less resistance to force in isotropic behavior due to the uniform direction of material fibers. Therefore, Neo-Hookean material showed less resistance leading to greater kinematics at the joint and higher strains in the ligaments.

One limitation of this study was that only one specific geometry for each ligament was used. While these materials properties have shown satisfactory results in five different models, future efforts can increase accuracy by optimizing the properties for each model separately and using subject-specific material coefficients, or providing a statistically relevant aggregate set of coefficients for each ligament. Another limitation concerns the use of uniaxial tensile data for determining the model coefficients where biaxial data may provide more robust 
coefficients by considering transverse properties of the ligaments in tension. However, as has been shown by other researchers, there is a lack of biaxial test data in the literature for knee ligaments [19]. Lastly, error sources are associated with 3D geometry creation from medical images, such as inaccuracies in segmenting and smoothing, which could affect the results.

\section{Conclusion}

The coefficients of the HGO material model for the knee cruciate and collateral ligaments were presented in this study using optimization techniques for the use in the knee finite element models while including the viscoelastic properties. When used in finite element simulations of bipedal landing, these coefficients provided closer agreement with the in-vitro experiments for the joint kinematics and ligaments strains relative to the Neo-Hookean materials. Future works may expand upon this study by performing subject-specific optimizations. Also, having access to the tensile test experiment data from a younger population will lead to more accurate optimization results for investigating young athletes' biomechanics. Therefore, future studies may perform updated tensile test experiments and then redo the optimization to explore the effects on the optimized coefficients.

\section{Acknowledgements}

The authors would like to thank Timothy Hewett, Mayo Clinic, Rochester, MN, and his coworkers for providing the CT and MRI images of the subjects and the results of their cadaver study that were used to validate our FE models.

The authors acknowledge partial funding support from the National Institutes of Health (NIH) Grant R01 AR0056259-05A1.

\section{Conflicts of Interest}

There has been no conflict of interest regarding the content of this article.

\section{References}

[1] Anderson, A.E., Ellis, B.J. and Weiss, J.A. (2007) Verification, Validation and Sensitivity Studies in Computational Biomechanics. Computer Methods in Biomechanics and Biomedical Engineering, 10, 171-184.

https://doi.org/10.1080/10255840601160484

[2] Erdemir, A., Guess, T.M., Halloran, J., Tadepalli, S.C. and Morrison, T.M. (2012) Considerations for Reporting Finite Element Analysis Studies in Biomechanics. Journal of Biomechanics, 45, 625-633. https://doi.org/10.1016/j.jbiomech.2011.11.038

[3] Kiapour, A., et al. (2014) Finite Element Model of the Knee for Investigation of Injury Mechanisms: Development and Validation. Journal of Biomechanical Engineering, 136, Article ID: 011002. https://doi.org/10.1115/1.4025692

[4] Freutel, M., Schmidt, H., Dürselen, L., Ignatius, A. and Galbusera, F. (2014) Finite Element Modeling of Soft Tissues: Material Models, Tissue Interaction and Challenges. Clinical Biomechanics, 29, 363-372.

https://doi.org/10.1016/j.clinbiomech.2014.01.006 
[5] Galbusera, F., et al. (2014) Material Models and Properties in the Finite Element Analysis of Knee Ligaments: A Literature Review. Frontiers in Bioengineering and Biotechnology, 2, 54. https://doi.org/10.3389/fbioe.2014.00054

[6] Bendjaballah, M., Shirazi-Adl, A. and Zukor, D. (1995) Biomechanics of the Human Knee Joint in Compression: Reconstruction, Mesh Generation and Finite Element Analysis. The Knee, 2, 69-79. https://doi.org/10.1016/0968-0160(95)00018-K

[7] Haut Donahue, T.L., Hull, M., Rashid, M.M. and Jacobs, C.R. (2002) A Finite Element Model of the Human Knee Joint for the Study of Tibio-Femoral Contact. Journal of Biomechanical Engineering, 124, 273-280.

https://doi.org/10.1115/1.1470171

[8] Wismans, J., Veldpaus, F., Janssen, J., Huson, A. and Struben, P. (1980) A ThreeDimensional Mathematical Model of the Knee-Joint. Journal of Biomechanics, 13, 677-685. https://doi.org/10.1016/0021-9290(80)90354-1

[9] Pandy, M.G., Sasaki, K. and Kim, S. (1997) A Three-Dimensional Musculoskeletal Model of the Human Knee Joint. Part 1: Theoretical Construction. Computer Methods in Biomechanics and Bio Medical Engineering, 1, 87-108. https://doi.org/10.1080/01495739708936697

[10] Li, G., Gil, J., Kanamori, A. and Woo, S.-Y. (1999) A Validated Three-Dimensional Computational Model of a Human Knee Joint. Journal of Biomechanical Engineering, 121, 657-662. https://doi.org/10.1115/1.2800871

[11] Blankevoort, L., Kuiper, J., Huiskes, R. and Grootenboer, H. (1991) Articular Contact in a Three-Dimensional Model of the Knee. Journal of Biomechanics, 24, 1019 1031. https://doi.org/10.1016/0021-9290(91)90019-J

[12] Mootanah, R., et al. (2014) Development and Validation of a Computational Model of the Knee Joint for the Evaluation of Surgical Treatments for Osteoarthritis. Computer Methods in Biomechanics and Biomedical Engineering, 17, 1502-1517. https://doi.org/10.1080/10255842.2014.899588

[13] Beidokhti, H.N., et al. (2016) A Comparison between Dynamic Implicit and Explicit Finite Element Simulations of the Native Knee Joint. Medical Engineering \& Physics, 38, 1123-1130. https://doi.org/10.1016/j.medengphy.2016.06.001

[14] Li, L., Yang, L., Zhang, K., Zhu, L., Wang, X. and Jiang, Q. (2020) Three-Dimensional Finite-Element Analysis of Aggravating Medial Meniscus Tears on Knee Osteoarthritis. Journal of Orthopaedic Translation, 20, 47-55. https://doi.org/10.1016/j.jot.2019.06.007

[15] Pena, E., Calvo, B., Martinez, M., Palanca, D. and Doblaré, M. (2005) Finite Element Analysis of the Effect of Meniscal Tears and Meniscectomies on Human Knee Biomechanics. Clinical Biomechanics, 20, 498-507.

https://doi.org/10.1016/j.clinbiomech.2005.01.009

[16] Shriram, D., Kumar, G.P., Cui, F., Lee, Y.H.D. and Subburaj, K. (2017) Evaluating the Effects of Material Properties of Artificial Meniscal Implant in the Human Knee Joint Using Finite Element Analysis. Scientific Reports, 7, Article No. 6011. https://doi.org/10.1038/s41598-017-06271-3

[17] Liu, X. and Zhang, M. (2013) Redistribution of Knee Stress Using Laterally Wedged Insole Intervention: Finite Element Analysis of Knee-Ankle-Foot Complex. Clinical Biomechanics, 28, 61-67. https://doi.org/10.1016/j.clinbiomech.2012.10.004

[18] Chizari, M., Snow, M. and Wang, B. (2011) Post-Operative Assessment of an Implant Fixation in Anterior Cruciate Ligament Reconstructive Surgery. Journal of Medical Systems, 35, 941-947. https://doi.org/10.1007/s10916-010-9514-Z

[19] Kiapour, A.M., et al. (2014) The Effect of Ligament Modeling Technique on Knee 
Joint Kinematics: A Finite Element Study. Applied Mathematics, 4, 91. https://doi.org/10.4236/am.2013.45A011

[20] Westermann, R.W., Wolf, B.R. and Elkins, J.M. (2013) Effect of ACL Reconstruction Graft Size on Simulated Lachman Testing: A Finite Element Analysis. The Iowa Orthopaedic Journal, 33, 70.

[21] Pena, E., Calvo, B., Martinez, M. and Doblare, M. (2006) A Three-Dimensional Finite Element Analysis of the Combined Behavior of Ligaments and Menisci in the Healthy Human Knee Joint. Journal of Biomechanics, 39, 1686-1701.

https://doi.org/10.1016/j.jbiomech.2005.04.030

[22] Dhaher, Y.Y., Kwon, T.-H. and Barry, M. (2010) The Effect of Connective Tissue Material Uncertainties on Knee Joint Mechanics under Isolated Loading Conditions. Journal of Biomechanics, 43, 3118-3125.

https://doi.org/10.1016/j.jbiomech.2010.08.005

[23] Limbert, G., Taylor, M. and Middleton, J. (2004) Three-Dimensional Finite Element Modelling of the Human ACL: Simulation of Passive Knee Flexion with a Stressed and Stress-Free ACL. Journal of Biomechanics, 37, 1723-1731.

https://doi.org/10.1016/j.jbiomech.2004.01.030

[24] Wan, C., Hao, Z., Tong, L., Lin, J., Li, Z. and Wen, S. (2015) An Update on the Constitutive Relation of Ligament Tissues with the Effects of Collagen Types. Journal of the Mechanical Behavior of Biomedical Materials, 50, 255-267. https://doi.org/10.1016/j.jmbbm.2015.06.018

[25] Beidokhti, H.N., Janssen, D., van de Groes, S., Hazrati, J., Van den Boogaard, T. and Verdonschot, N. (2017) The Influence of Ligament Modelling Strategies on the Predictive Capability of Finite Element Models of the Human Knee Joint. Journal of Biomechanics, 65, 1-11. https://doi.org/10.1016/j.jbiomech.2017.08.030

[26] Limbert, G. (2001) Finite Element Modelling of Biological Soft Connective Tissues. Application to the Ligaments of the Human Knee. Ph.D. Thesis, School of Engineering Sciences, University of Southampton, Southampton.

[27] Holzapfel, G.A., Gasser, T.C. and Ogden, R.W. (2000) A New Constitutive Framework for Arterial Wall Mechanics and a Comparative Study of Material Models. Journal of Elasticity and the Physical Science of Solids, 61, 1-48. https://doi.org/10.1007/0-306-48389-0_1

[28] Provenzano, P., Lakes, R. and Keenan, T. (2001) Nonlinear Ligament Viscoelasticity. Annals of Biomedical Engineering, 29, 908-914. https://doi.org/10.1114/1.1408926

[29] DeFrate, L. and Li, G. (2007) The Prediction of Stress-Relaxation of Ligaments and Tendons Using the Quasi-Linear Viscoelastic Model. Biomechanics and Modeling in Mechanobiology, 6, 245-251. https://doi.org/10.1007/s10237-006-0056-8

[30] Peña, E., Pena, J. and Doblaré, M. (2008) On Modelling Nonlinear Viscoelastic Effects in Ligaments. Journal of Biomechanics, 41, 2659-2666.

https://doi.org/10.1016/j.jbiomech.2008.06.019

[31] Wang, X., Chen, X., Hodgson, P. and Wen, C. (2006) Elastic Modulus and Hardness of Cortical and Trabecular Bovine Bone Measured by Nanoindentation. Transactions of Nonferrous Metals Society of China, 16, s744-s748. https://doi.org/10.1016/S1003-6326(06)60293-8

[32] Woo, S.L.-Y., Hollis, J.M., Adams, D.J., Lyon, R.M. and Takai, S. (1991) Tensile Properties of the Human Femur-Anterior Cruciate Ligament-Tibia Complex: The Effects of Specimen Age and Orientation. The American Journal of Sports Medicine, 19, 217-225. https://doi.org/10.1177/036354659101900303 
[33] Quapp, K. and Weiss, J. (1998) Material Characterization of Human Medial Collateral Ligament. Journal of Biomechanical Engineering, 120, 757-763. https://doi.org/10.1115/1.2834890

[34] Erbulut, D.U., Sadeqi, S., Summers, R. and Goel, V.K. (2021) Tibiofemoral Cartilage Contact Pressures in Athletes during Landing: A Dynamic Finite Element Study. Journal of Biomechanical Engineering, 143, Article ID: 101006. https://doi.org/10.1115/1.4051231

[35] Bates, N.A., Schilaty, N.D., Nagelli, C.V., Krych, A.J. and Hewett, T.E. (2017) Novel Mechanical Impact Simulator Designed to Generate Clinically Relevant Anterior Cruciate Ligament Ruptures. Clinical Biomechanics, 44, 36-44.

https://doi.org/10.1016/j.clinbiomech.2017.03.005

[36] Gasser, T.C., Ogden, R.W. and Holzapfel, G.A. (2006) Hyperelastic Modelling of Arterial Layers with Distributed Collagen Fibre Orientations. Journal of the Royal Society Interface, 3, 15-35. https://doi.org/10.1098/rsif.2005.0073

[37] Hooke, R. and Jeeves, T.A. (1961) Direct Search Solution of Numerical and Statistical Problems. Journal of the ACM (JACM), 8, 212-229.

https://doi.org/10.1145/321062.321069

[38] Evans, D.W., Moran, E.C., Baptista, P.M., Soker, S. and Sparks, J.L. (2013) ScaleDependent Mechanical Properties of Native and Decellularized Liver Tissue. Biomechanics and Modeling in Mechanobiology, 12, 569-580. https://doi.org/10.1007/s10237-012-0426-3

[39] Vetrano, S. and Silver-Thorn, M. (1997) Analysis of Residual Limb Bulk Soft Tissue Behavior Using Nonlinear Finite Element Methods. Asme-Publications-Bed, 35, 201-202.

[40] Burkhart, T.A., Andrews, D.M. and Dunning, C.E. (2013) Finite Element Modeling Mesh Quality, Energy Balance and Validation Methods: A Review with Recommendations Associated with the Modeling of Bone Tissue. Journal of Biomechanics, 46, 1477-1488. https://doi.org/10.1016/j.jbiomech.2013.03.022

[41] Donahue, T.L.H., Hull, M., Rashid, M.M. and Jacobs, C.R. (2003) How the Stiffness of Meniscal Attachments and Meniscal Material Properties Affect Tibio-Femoral Contact Pressure Computed Using a Validated Finite Element Model of the Human Knee Joint. Journal of Biomechanics, 36, 19-34. https://doi.org/10.1016/S0021-9290(02)00305-6

[42] Shepherd, D. and Seedhom, B. (1999) The "Instantaneous" Compressive Modulus of Human Articular Cartilage in Joints of the Lower Limb. Rheumatology (Oxford, England), 38, 124-132. https://doi.org/10.1093/rheumatology/38.2.124

[43] Van Dommelen, J., et al. (2005) Pedestrian Injuries: Viscoelastic Properties of Human Knee Ligaments at High Loading Rates. Traffic Injury Prevention, 6, 278-287. https://doi.org/10.1080/15389580590969436

[44] Ohio Supercomputer Center (1987) http://osc.edu/ark:/19495/f5s1ph73

[45] Krosshaug, T., Slauterbeck, J.R., Engebretsen, L. and Bahr, R. (2007) Biomechanical Analysis of Anterior Cruciate Ligament Injury Mechanisms: Three-Dimensional Motion Reconstruction from Video Sequences. Scandinavian Journal of Medicine \& Science in Sports, 17, 508-519. https://doi.org/10.1111/j.1600-0838.2006.00558.x

[46] Hewett, T.E., Torg, J.S. and Boden, B.P. (2009) Video Analysis of Trunk and Knee Motion during Non-Contact Anterior Cruciate Ligament Injury in Female Athletes: Lateral Trunk and Knee Abduction Motion Are Combined Components of the Injury Mechanism. British Journal of Sports Medicine, 43, 417-422. https://doi.org/10.1136/bjsm.2009.059162 
[47] Delingette, H. (1998) Toward Realistic Soft-Tissue Modeling in Medical Simulation. Proceedings of the IEEE, 86, 512-523. https://doi.org/10.1109/5.662876

[48] Wilson, W.T., Deakin, A.H., Payne, A.P., Picard, F. and Wearing, S.C. (2012) Comparative Analysis of the Structural Properties of the Collateral Ligaments of the Human Knee. Journal of Orthopaedic \& Sports Physical Therapy, 42, 345-351. https://doi.org/10.2519/jospt.2012.3919

[49] Smeets, K., Slane, J., Scheys, L., Claes, S. and Bellemans, J. (2017) Mechanical Analysis of Extra-Articular Knee Ligaments. Part One: Native Knee Ligaments. The Knee, 24, 949-956. https://doi.org/10.1016/j.knee.2017.07.013

[50] Cho, H.-J. and Kwak, D.-S. (2020) Mechanical Properties and Characteristics of the Anterolateral and Collateral Ligaments of the Knee. Applied Sciences, 10, 6266. https://doi.org/10.3390/app10186266

[51] Mommersteeg, T., Blankevoort, L., Huiskes, R., Kooloos, J. and Kauer, J. (1996) Characterization of the Mechanical Behavior of Human Knee Ligaments: A Numerical-Experimental Approach. Journal of Biomechanics, 29, 151-160. https://doi.org/10.1016/0021-9290(95)00040-2

[52] Ogden, R., Saccomandi, G. and Sgura, I. (2004) Fitting Hyperelastic Models to Experimental Data. Computational Mechanics, 34, 484-502.

https://doi.org/10.1007/s00466-004-0593-y

[53] Marieswaran, M., et al. (2018) Effect of Preservation Methods on Tensile Properties of Human Femur-ACL-Tibial Complex (FATC) - A Cadaveric Study on Male Subjects. Acta of Bioengineering and Biomechanics, 20, 31-42.

[54] Butler, D., Sheh, M., Stouffer, D., Samaranayake, V. and Levy, M.S. (1990) Surface Strain Variation in Human Patellar Tendon and Knee Cruciate Ligaments. Journal of Biomechanical Engineering, 112, 38-45. https://doi.org/10.1115/1.2891124

[55] Pena, E., Calvo, B., Martínez, M. and Doblaré, M. (2007) An Anisotropic Visco-Hyperelastic Model for Ligaments at Finite Strains. Formulation and Computational Aspects. International Journal of Solids and Structures, 44, 760-778.

https://doi.org/10.1016/j.ijsolstr.2006.05.018 